UCRL-JC-120144

PREPRINT

\title{
Safety and Security Issues in Developing and Operating in Intelligent Transportation Systems
}

\author{
RECEIVED \\ J. Dennis Lawrence \\ OCT 161995 \\ OSTI \\ This paper was prepared for submittal to the \\ 10th Annual IEEE Conference on Computer Assurance \\ National Institute of Standards and Technology, Gaithersburg, Maryland \\ June 26-30, 1995
}

April 1995

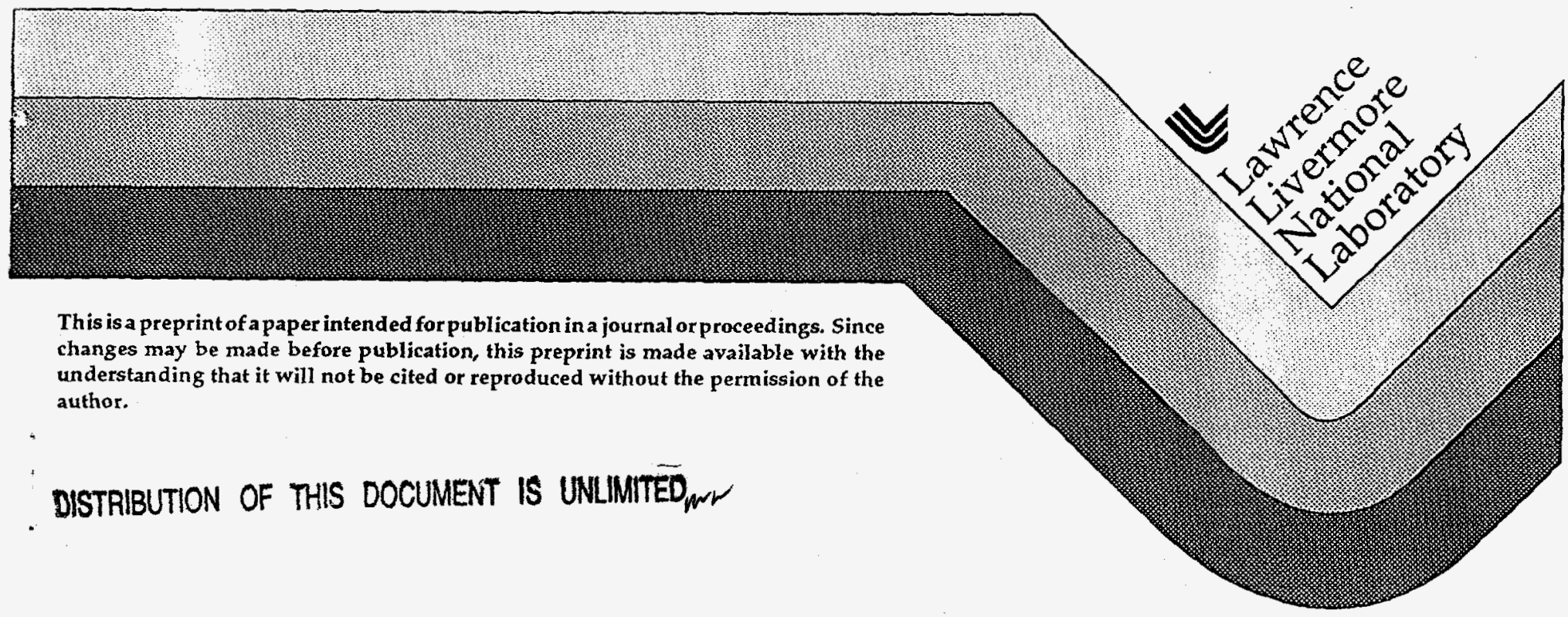

This is a preprint of a paper intended for publication in a journal or proceedings. Since changes may be made before publication, this preprint is made available with the understanding that it will not be cited or reproduced without the permission of the author.

DISTRIBUTION OF THIS DOCUMENT IS UNLIMITED 


\section{DISCLAIMER}

This document was prepared as an account of work sponsored by an agency of the United States Government. Neither the United States Government nor the University of California nor any of their employees, makes any warranty, express or implied, or assumes any legal liability or responsibility for the accuracy, completeness, or usefulness of any information, apparatus, product, or rpocess disclosed, or represents

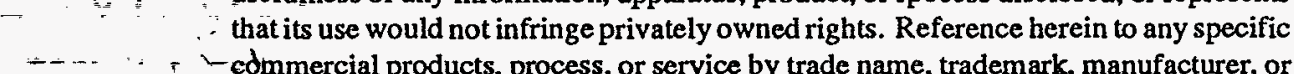
otherwise, does not necessarily constitute or imply its endorsement, recommendation, or favoring by the United States Government or the University of California. The views and opinions of authors expressed herein do not necessarily state or reflect those of the United States Government or the University of California, and shall not be used for advertising or product endorsement purposes. 


\section{DISCLAIMER}

Portions of this document may be illegible in electronic image products. Images are produced from the best available original document. 


\title{
Position Statement \\ Safety and Security Issues in Developing and Operating in Intelligent Transportation Systems
}

\author{
J. Dennis Lawrence, Lawrence Livermore National Laboratory
}

\section{Problem Statement}

The purpose of this panel is to introduce the safety and security issues related to the development and operation of Intelligent Transportation Systems (ITS) to Compass participants. Many of these issues need to be addressed by the system safety and computer security communities prior to the development and deployment of ITS. For example, how can information technology be applied in the context of a fully automated highway system (AHS) such that the safety, security, and performance of the system are not compromised? At present, the U.S. and other countries are funding academia and industry to build prototype automated highway systems in which vehicles are controlled via drive-by-wire technology, with vehicles traveling at high speeds (in excess of $\mathbf{3 0}$ $\mathrm{m} / \mathrm{s}$ ) at close spacing $(1$ to $4 \mathrm{~m}$ ). The potential impact of software errors or hardware errors on system safety and security are great.

\section{Background}

In the past, the problem of providing increased mobility for travelers on U.S. highways was solved by increasing the size of the existing roadway infrastructure via the construction of new roadways and bridges. The constraints and forces affecting surface transportation at that time seemed manageable because of the relative ease with which government agencies could obtain the necessary right-of-way and roadway construction funding. Over time, however, these constraints and forces have shifted, making such an solution untenable from political, economic, and environmental perspectives. For example, in some densely populated urban areas, it is not economically feasible to purchase the land upon which to construct one or more new lanes along existing lanes, or the impact to the environment, such in wet lands, precludes any type of construction. Moreover, due to such factors as induced demand, additional lanes and bridges do not, in their own right, help to reduce highway congestion, improve highway safety, or minimize vehicle emissions.

Recently, the surface transportation community in the United States has begun to rely more and more heavily on the use of information technology to address highway congestion, highway safety, and vehicle emission issues. Congress also recognized the need for solutions and, in 1991, passed the Intermodal Surface Transportation Efficiency Act of 1991, known as ISTEA. ISTEA authorizes completion of the Interstate Highway System, and authorizes $\$ 155$ billion in expenditures over six years. ISTEA also contains the IVHS Act -- the Intelligent VehicleHighway System (IVHS) Act. Since the passage of the Act, the name IVHS has been changed to Intelligent Transportation System (ITS) to better reflect the multi- and intermodal aspects of surface transportation (e.g., to encompassing transit and trucking and their integration with other modes of transport). One way to categorize types of ITS is by function, as given below.

Advanced Traffic Management Systems (ATMS) integrate management of roadway functions such as integrated signal controls, priorities for highoccupancy vehicles, ramp meters, and traffic congestion and incident monitoring.

Advanced Traveler Information Systems (ATIS) work with ATMS to provide information that assists travelers in reaching their destinations by private vehicles, public transit, or an intermodal combination.

Advanced Public Transportation Systems (APTS) - encourage transit use by improving the timeliness and accessibility of information about transit schedules and availability and traffic conditions for alternative modes of transportation.

Advanced Rural Transportation Systems (ARTS) - respond to the special needs of rural areas, which contain the majority of U.S. highway 
miles. ARTS applications include automated mayday signals, accident detection and automatic vehicte location, and hazard warning.

Advanced Vehicle Control Systems (AVCS) enhance driver control for safety and efficiency. AVCS aims to avoid accidents, not merely ameliorate their consequences.

Commercial Vehicle Operations (CVO) constitute the ITS functions of concern to fleets, trucks, buses, vans, taxis, and emergency vehicles.

The Intelligent Transportation Society of America (ITS AMERICA) is the institutional embodiment of ITS in the United States and is a focal point for advanced surface transportation around the world. It is a forum in which industry, government, and academia meet to build consensus on developing and deploying ITS. Among its many roles, ITS AMERICA is a utilized Federal Advisory Committee to the U.S. Department of Transportation (DOT) on the ITS Program. Within this capacity, ITS AMERICA assisted U.S. DOT in developing an ITS Strategic Plan, as directed by Congress. Most quoted among the forecasts in this plan is that more than $\$ 200$ billion will be invested in ITS development and deployment in the United States over the next 20 years.

Jointly developed by ITS AMERICA and the U.S. DOT was the National Program Plan for ITS. Inherent to this plan is a list and description of 29 User Services. These User Services define the ITS Program more precisely than the functional areas defined above. The User Services have been appropriately "bundled" and are summarized in the table below.

Based on the ITS functional areas listed above and the User Services outlined below, it can be seen that the operating environments of ITS are generally expected to involve multiple interconnected computer systems built by multiple independent developers which are widely dispersed geographically and temporally. A hypothetical example of this is emergency vehicle routing on the Washington D.C. beltway. Suppose all the Maryland counties (except one in the middle) have agreed on a single system for highway surveillance, automated accident detection and automated routing of emergency vehicles. The exception purchased a different system, several years before the larger Maryland system was obtained. Each Virginia county goes its own way and at different times, spread over a decade. All these systems are expected to cooperate in meeting the overall emergency management goals.

There are obvious problems of intra- and intersystem compatibility and communication of multiple computer systems from multiple vendors built at different times intended to service multiple ITS goals. There are also important problems of security and safety that must be solved for many of the goals. In many cases, security and safety are tightly linked. Imagine the impact on safety of an intruder in the Emergency Vehicle Routing System.

*This work was performed under the auspices of the U.S. Department of Energy by Lawrence Livermore National Laboratory under contract No. W-7405-Eng-48. 
ITS User Service Bundles

\begin{tabular}{|c|c|}
\hline Bundle & User Services \\
\hline 1. Travel and Transportation Management & $\begin{array}{l}\text { 1. En-Route Driver Information } \\
\text { 2. Route Guidance } \\
\text { 3. Traveler Services Information } \\
\text { 4. Traffic Control } \\
\text { 5. Incident Management } \\
\text { 6. Emissions Testing and Mitigation }\end{array}$ \\
\hline 2. Travel Demand Management & $\begin{array}{l}\text { 1. Pre-Trip Travel Information } \\
\text { 2. Ride Matching and Reservation } \\
\text { 3. Demand Management and Operations }\end{array}$ \\
\hline $\begin{array}{rcc}\text { 3. Advanced Public Transportation } \\
\text { Operations } \\
\end{array}$ & $\begin{array}{l}\text { 1. Public Transportation Management } \\
\text { 2. En-Route Transit Information } \\
\text { 3. Personalized Public Transit } \\
\text { 4. Public Travel Security }\end{array}$ \\
\hline 4. Electronic Payment & 1. Electronic Payment Services \\
\hline 5. Commercial Vehicle Operations & $\begin{array}{l}\text { 1. Commercial Vehicle Electronic Clearance } \\
\text { 2. Automated Roadside Safety Inspection } \\
\text { 3. On-board Safety Monitoring } \\
\text { 4. Commercial Vehicle Administrative Processes } \\
\text { 5. Hazardous Materials Incident Response } \\
\text { 6. Commercial Fleet Management }\end{array}$ \\
\hline 6. Emergency Management & $\begin{array}{l}\text { 1. Emergency Notification and Personal Security } \\
\text { 2. Emergency Vehicle Management }\end{array}$ \\
\hline $\begin{array}{l}\text { 7. Advanced Vehicle Control and Safety } \\
\text { Systems }\end{array}$ & $\begin{array}{l}\text { 1. Longitudinal Collision Avoidance } \\
\text { 2. Lateral Collision Avoidance } \\
\text { 3. Intersection Collision Avoidance } \\
\text { 4. Vision Enhancement for Crash Avoidance } \\
\text { 5. Safety Readiness } \\
\text { 6. Pre-Crash Restraint Deployment } \\
\text { 7. Automated Highway System }\end{array}$ \\
\hline
\end{tabular}

